\title{
Payne e Faleiros: dois olhares para o Serviço Social
}

\section{Payne and Faleiros: two looks for Social Work}

\author{
Ludson Rocha Martins ${ }^{a}$ \\ (D) https://orcid.org/0000-0002-7484-8341
}

\begin{abstract}
Resumo: $O$ texto recupera as linhas básicas do pensamento de Malcom Payne e Vicente Faleiros sobre os fundamentos do Serviço Social. Nesse caminho, enfatiza as diferenças entre as tradições que representam, aborda a forma como trabalham o universo teórico da profissão, as forças responsáveis por sua origem e desenvolvimento, bem como concebem o objeto e o concurso da atuação dos assistentes sociais.
\end{abstract}

Palavras-chave: Serviço Social. Malcom Payne. Vicente Faleiros.

\begin{abstract}
The paper recovers the basic lines of thought of Malcom Payne and Vicente Faleiros on the foundations of Social Work. In this way, it emphasizes the differences between the traditions they represent, it also addresses how the theoretical universe of the profession works, the forces responsible for its origin and development, as well as conceiving of the object and the contest of the action two social workers.
\end{abstract}

Keywords: Social Work. Malcom Payne. Vicente Faleiros.

\section{Introdução}

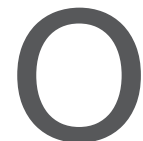

desenvolvimento recente do Serviço Social brasileiro, levado a cabo pelas vanguardas profissionais, envolveu rupturas diversas: com o conservadorismo ideológico e político que tanto marcou a categoria; com as perspectivas tradicionais que a atravessavam; com o confessionalismo religioso típico das suas protoformas etc.

A ruptura teórica, especificamente, concretizou-se, comportando a recusa à importação não mediatizada de visões exteriores a realidade latino-americana referentes ao Serviço Social europeu e estadunidense - que se materializou na crítica à influência do positivismo, da psicanálise, bem 
como das metodologias de caso, grupo e comunidade no país, resultando no surgimento de uma literatura eminentemente local (Martins, 2014).

Tal dinâmica, no entanto, se consolidou com um efeito negativo: tornar o debate nacional pouco permeável às elaborações europeias e norte-americanas (sendo particularmente difícil, inclusive, encontrar traduções de obras contemporâneas dessas regiões no Brasil). ${ }^{1}$

Paradoxalmente, o Serviço Social brasileiro ampliou sua influência teórica em nível global, sedimentada pelo número de mestrados e doutorados do país, pelas iniciativas da Associação Brasileira de Ensino e Pesquisa em Serviço Social (Abepss) e pela estrutura de proteção e promoção ocupacional do conjunto CFESS/Cress, ${ }^{2}$ com sua política de relações internacionais. ${ }^{3}$

Ou seja, embora relativamente distante do cenário teórico do Velho Mundo e dos Estados Unidos, parece provável que o debate brasileiro seja interpelado, até pela difusão que alcançou, com as produções atuais dessas tradições, sendo necessário desde já estabelecer os termos de tal interlocução, seja para evitar provincianismos, seja para garantir a posição de autonomia e os acúmulos já alcançados (Martins, 2014 e 2016).

É nessa conjuntura que o presente texto se propõe a analisar duas perspectivas sobre os fundamentos do Serviço Social, avaliando a maneira como trabalham o universo teórico da profissão. Trata-se de abordar o pensamento de Vicente Faleiros (um dos mais conhecidos nomes da profissão no Brasil) e o de Malcom Payne, importante teórico do Serviço Social nos países anglo-saxões (sobretudo por seus esforços relativos à historiografia da categoria e pela apresentação de diferentes teorias relacionadas à prática profissional).

Cabe esclarecer que a escolha de tais autores não foi ocasional. No país, Faleiros (2007, 2009 e 2013) é quem mais dialoga com o conjunto do debate das Ciências Sociais e com o Serviço Social internacional, tendo se dedicado

\footnotetext{
1 O que nos fez recorrer a obras publicadas em Portugal ou acessar textos em inglês.

Conselho Federal de Serviço Social/Conselhos Regionais de Serviço Social.

3 Sobre a política de relações internacionais do conjunto e a difusão do pensamento nacional, ver o texto de Teixeira (2007).
} 
recentemente a este assunto. Payne (2002), por outro lado, possui extenso contato com obras diversas da categoria, não sendo a ele estranho o debate marxista brasileiro e latino-americano (como demonstra o livro Teoria do trabalho social moderno, que possui capítulo focado nessa questão).

Em outras palavras, são nomes significativos, capazes de exemplificar os espaços e visões às quais estão vinculados. Neste sentido, como se procurará evidenciar, o contraste entre seus pensamentos pode culminar em possibilidades e contributos relevantes para o debate profissional.

\section{O pensamento de Malcom Payne sobre o Serviço Social}

Malcom Payne pode ser visto como um nome de grande difusão no universo do Serviço Social, sobretudo no âmbito da língua inglesa. Nascido em 13 de julho de 1947, na Polônia, possui experiência na área da saúde mental (foi diretor psicossocial do St. Christopher's Hospice, em Londres), apresentando ainda longa trajetória de atuação com comunidades. No campo acadêmico, lecionou na Manchester Metropolitan University e St. George's, University of London. Publicou ainda diversos livros, comunicações e artigos.

Em sua produção podemos destacar obras como Social Work and community care, ${ }^{4}$ de 1995; What is professional Social Work?, ${ }^{5}$ de 2007; Humanistic Social Work: core principles in practice, ${ }^{6}$ de 2011, e, sobretudo, Teoria do trabalho social moderno, de 1990.?

Um alerta é essencial para a correta abordagem do autor. Não se deve confundir sua perspectiva com o antigo conservadorismo do Serviço Social. Se é inegável que a profissão, na Europa e Estados Unidos, se ergueu a partir

4 Que discute as características e processos práticos do trabalho com comunidades (bem como suas requisições em termos de habilidades técnicas e interpessoais) (Payne, 1995).

5 Livro que procura desenvolver a temática da identidade do assistente social, a natureza da profissão de Serviço Social em comparação com outras profissões de ajuda, no contexto do desenvolvimento do Serviço Social norte-americano (Payne, 2007).

6 Em que Payne (2011) procura elaborar princípios para uma intervenção profissional “humanista", isto é, uma atuação com foco na satisfação positiva de demandas oriundas de relações sociais.

7 A tradução da segunda edição foi publicada em Portugal, em 2002, e concentrará nossa atenção. 
de perspectivas conservadoras, é preciso compreender que tal realidade se complexificou bastante.

Também nesses lugares o confessionalismo religioso das pioneiras e a visão higienista de Mary Richmond - com seus seguidores positivistas não se sustentou (sobretudo pelas suas próprias debilidades) (Martins, 2017). Se o conservadorismo permanece forte é porque se transformou, possui atualmente outras características - desenvolvidas com base no aprofundamento da relação da profissão com a psicanálise, com as perspectivas pós-modernas, bem como pelo surgimento de correntes profissionais de cariz gerencialista (Ferguson, 2011). Tal conservadorismo, inclusive, entra em embate com abordagens feministas de Serviço Social; com correntes ligadas a outros movimentos de minorias (como o negro e o LGBT), bem como com visões marxistas, postas pelo chamado Radical Social Work. ${ }^{8}$

Payne (2002 e 2011) deve ser visto nessa conjuntura mais ampla, de modo que seus trabalhos não podem ser reduzidos às limitações do tradicionalismo profissional, independente dos limites que os afetam.

Em Teoria do trabalho social moderno, o autor apresenta uma provocação importante: "Será o trabalho social uma entidade singular, a mesma coisa em todas as sociedades?". Com esta pergunta ele chama a atenção para o fato de a profissão ser uma construção social.

Diz ele:

[...] argumento que os profissionais e clientes constroem o trabalho social dentro do contexto das suas instituições. No entanto, não é construído de novo sempre que um profissional e um cliente se encontram num contexto institucional. Isto é, porque cada profissional, cliente e contexto institucional são eles próprios construídos pela sociedade em que existem. $O$ que eles fazem é formado por expectativas extraídas da sociedade. E contribuem até certo

8 De acordo com Ferguson (2011, p. 37) "O Serviço Social radical, como um modelo ou abordagem distinta e conscientemente articulada dentro do Serviço Social, surgiu de fato nos anos 1970, principalmente na Inglaterra, Canadá e Austrália”, e em menor medida nos Estados Unidos. Trata-se de um conjunto múltiplo de abordagens estimuladas pelos movimentos de minorias e direitos civis, bem como pelo pensamento marxista. 
ponto para as expectativas dessa sociedade através do seu próprio pensamento e ação. Esse é o processo da construção do trabalho social. (Payne, 2002, p. 17).

De acordo com Payne (2002), não apenas o Serviço Social é um produto específico da ação humana, mas um constructo que varia no tempo e no espaço. Assim, por exemplo, as regras e convenções que regem a categoria no Ocidente não são necessariamente válidas para outras sociedades, posto que nestas existem problemas e questões distintas.

Senão vejamos:

O trabalho social euroamericano presume que um leque de serviços de assistência estatais está disponível num país relativamente rico e economicamente desenvolvido. Frequentemente, concentra-se nos problemas sociais das sociedades urbanizadas. Predominantemente rurais, as sociedades subdesenvolvidas em que a subsistência, a saúde básica e as necessidades de sobrevivência são um problema, não podem, provavelmente, utilizar os métodos postos em prática pelo trabalho social ocidental. É necessário algo diferente. A incapacidade do trabalho social ocidental de fornecer modelos viáveis e uma formação adequada tem sido criticada, especialmente em assuntos de desenvolvimento rural e mudança social. (Payne, 2002, p. 27)

Com as tais assertivas, Payne (2002) identifica três grandes blocos de visões sobre o Serviço Social, cada qual congregando teorias variadas. 0 primeiro diz respeito à perspectiva tradicional da profissão, conformando-se enquanto um conjunto de visões reflexivo-terapêuticas:

Estas veem o trabalho social procurando, através da promoção e da facilitação do crescimento e da realização pessoal, um melhor bem-estar na sociedade para os indivíduos, grupos e comunidades. Um processo constante de interação com outros profissionais modifica as suas ideias e permite-lhes influenciar outras ideias. Este processo de influência mútua é o que torna o trabalho social reflexivo. Por este meio, as pessoas ganham poder sobre os seus próprios sentimentos e sobre a sua forma de vida. (Payne, 2002, p. 20)

Temos aqui o velho paradigma do ajustamento, com a psicologização das relações sociais, o voluntarismo e o superdimensionamento dos efeitos da 
intervenção profissional, que reduzem os problemas sociais as dificuldades do indivíduo para se adaptar às requisições de seu meio. 0 próprio Payne (2002) reconhece os limites dessas ideias, indicando que seriam criticadas e disputadas por outras correntes mais complexas.

A segunda perspectiva, nesse tocante, seria formada por visões socialistas-coletivistas (isto é, marxistas) que

encaram o trabalho social como estando em busca de cooperação e apoio mútuo na sociedade, de forma a que as pessoas mais oprimidas e desfavorecidas possam conquistar poder sobre suas vidas. No quadro desta perspectiva o trabalho social dá às pessoas a possibilidade de tomarem parte numa dinâmica de participação e cooperação num processo de criação de instituições de que todos possam usufruir. Controlam assim a tendência de que as elites têm para acumular o poder e perpetuar o benefício por si conquistado na utilização dos recursos sociais. Contrariando as práticas que criam opressão e desfavorecimento, o trabalho social tenta, deste modo, incrementar relações mais igualitárias na sociedade. (Payne, 2002, p. 21)

A terceira perspectiva, por sua vez, consubstanciaria visões individualistas-reformistas, que - baseadas na execução de políticas sociais públicas e privadas do Welfare State europeu - ampliariam o alcance das visões terapêuticas.

Em outros termos:

They see Social Work as maintaining the social order and social fabric of society, and maintaining people during any period of difficulties that they may be experiencing, so that they can recover stability again. This view expresses the liberal or rational economic political philosophy, that personal freedom in economic markets, supported by the rule of law, is the best way of organising societies. (Payne, 2007, p. 30)

O suposto de Payne (2002, p. 49) é de que as teorias do trabalho social são realidades imaginadas que podem ganhar concreção, dado que "existe uma aceitação partilhada de algumas ideias que, para fins práticos, as pessoas tratam como realidade". 
Nesse ponto Berger e Luckmann (2008) — e sua teoria do conhecimento e do reconhecimento social - são importantes bases para concepção do autor. Neles, cabe resgatar, a sociedade é apreendida como um constructo subjetivo e objetivo, que se manifesta de forma interior e exterior aos sujeitos.

A interiorização da realidade social é posta pelo processo de socialização, que inculca no indivíduo os padrões de ação e visão de mundo reconhecidos, além de situá-lo quanto a seu lugar na coletividade. O movimento contrário - de exteriorização das consciências individuais para o real - ocorreria a partir dos laços e disputas estabelecidas entre os sujeitos, os quais (por meio da repetição) objetificam formas partilhadas (isto é, meios de controle cristalizados em instituições) para conceber e enfrentar as questões postas pelo mundo social.

Daí que para Berger e Luckmann (2008) a produção e sistematização moderna do saber seja tomada como uma questão institucional, ou seja, o conhecimento, sobretudo o científico, seria socialmente afirmado como realidade, a partir de processos estruturados de desenvolvimento, transmissão e manutenção de padrões ideais hegemônicos.

Sob tal influência Payne (2011 e 2007) indica três vetores responsáveis pela produção da profissão. $O$ primeiro aspecto diz respeito à conformação do Serviço Social como profissão regulamentada e especializada, isto é, aos institutos que manifestam a profissionalidade do trabalho social. Formação acadêmica, deontologia, associações profissionais, reserva de mercado, são elementos que produzem o assistente social, sua prática e suas teorias. Este complexo se definiria, inclusive, pelas relações com outras ocupações, melhor ou pior colocadas que o Serviço Social, e que assentariam as bases de competição e colaboração que marcariam a conjuntura da profissão.

O segundo aspecto se refere ao caráter ativo — segundo Payne (2002) muito pouco notado - da intervenção dos usuários no Serviço Social. Para ele ser "cliente" é um processo por meio do qual um sujeito leva ou é levado a apresentar problemas de seu cotidiano para uma instituição social, que o integrará numa rede de atenção instrumentalizada por profissionais. As expectativas, valores e reações do usuário (que muitas vezes sequer se reconhece como tal) se confrontam com as teorias e posturas do assistente 
social, contribuindo para a formação do agente profissional e de sua própria ocupação em sentido amplo.

Em terceiro lugar Payne (2002) remete ao contexto que circunda o trabalho do assistente social, num primeiro nível a conjuntura institucional: o Serviço Social faz parte e interage constantemente com redes de instituições públicas e privadas (cada qual com seu modo de trabalho, história e cultura organizacional). Num segundo nível, essas instituições são impactadas por estruturas mais amplas de relações, que se reportam à dinâmica política, econômica e cultural da sociedade.

Nesse tópico há que se frisar o parco aprofundamento desenvolvido pelo autor, não se verificando detalhamento sobre os fatores e dinâmicas que levam o cenário social a determinar e produzir tanto o usuário, quanto o agente profissional, mas apenas aproximações parciais.

Do ponto de vista metodológico e epistemológico Payne (2002) observa o trabalho social como influenciado por dois conjuntos de lógicas científicas: a lógica positivista e a lógica pós-moderna. A visão positivista seria estática, focada na busca de evidências, quantificação, generalização de conceitos e rejeição à contaminação do pesquisador por emoções e valores externos ao objeto investigado. Já o pensamento pós-moderno seria marcado pela flexibilidade e ênfase na diversidade, partindo da consideração do papel social do conhecimento, enquanto representação da realidade e instrumento de poder.

É necessário dizer que a argumentação de Payne (2002, 2007 e 2011 é frágil, amalgamando no campo da lógica positivista pensadores como Weber e Habermas, além de deixar de lado outras escolas importantes do pensamento social — não compatíveis no campo lógico ao pós-modernismo —, como o interacionismo simbólico clássico ou o próprio marxismo.

O autor, em todo caso, se coloca no campo pós-moderno, vendo-o como um pensamento típico de "uma sociedade mais flexível, mas também mais fragmentada" que dá "grande importância ao trabalho baseado no conhecimento, e a uma heterogeneidade tanto dos valores sociais, como da forma de refletir sobre as estruturas" (Payne, 2002, p. 53).

Do ponto de vista do Serviço Social, isso significa dizer que a teoria, a prática e o corpus profissional consistem em relações significativas (postas 
principalmente pela incorporação de teorias mais amplas das ciências sociais), o que inclui a elaboração de práticas e verdades que formam relações de poder.

É interessante notar, inclusive, como o autor sintetiza sua própria visão de Serviço Social. Em What is professional Social Work? ele indica a atividade profissional como:

A service and practice using social and psychological sciences in interpersonal interactions with people, especially from deprived social groups and experiencing practical and emotional difficulties in social relationships. Social Work balances three objectives: maintaining social order and providing social welfare services effectively, helping people attain personal fulfilment and power over their lives and stimulating social change. (Payne, 2007, p. 5)

Ou seja, Payne (2007) observa o Serviço Social enquanto profissão mediadora de serviços, voltada para a satisfação de necessidades de reprodução social de sujeitos e grupos que possuem uma relação de conflito com a ordem coletiva. As possibilidades de intervenção (dependendo da visão teórica, dos interesses e ideologias do assistente social) podem ser direcionadas ao ajustamento dos sujeitos; a uma compatibilização (mesmo que precária) entre seus interesses individuais e as normas sociais (perspectiva reformista); ou à promoção da mudança social (a partir das expectativas e demandas dos agentes atendidos).

O problema surge da contradição explícita que marca a definição (que nada mais é do que uma junção dos três tipos de visão anteriormente trabalhados): manter a ordem, prestar serviços de bem-estar e, ao mesmo tempo, incentivar a mudança social.

Em todo caso, é com essas bases que Payne (2002) trabalha as especificidades das teorias do Serviço Social. De acordo com ele, estas se conformam a partir de enfoques mais alargados das ciências humanas. Tais abordagens são utilizadas pelos assistentes sociais para fundamentar um pensamento geral sobre a natureza e a ação profissional, e este, por sua vez, se relaciona com modelos que prescrevem a prática.

Daí que boa parte da obra do autor seja voltada para discutir estratégias de intervenção: abordagens de trabalho individual (chamada de intervenção 
centrada em tarefas); abordagens que fazem interface com a psicologia e promovem a incorporação de visões terapêuticas ao Serviço Social: gestalt, teoria de sistemas, teoria humanista, grupos terapêuticos etc., e ainda trabalho com comunidades e grupos, chamados por ele de perspectivas de empoderamento de minorias, ou baseadas nas experiências do Radical Social Work (Payne, 2002 e 2007).

Conforme Payne (2002), a internalização e o uso da teoria pelos profissionais são pontos eminentemente problemáticos, que remetem aos dilemas da relação entre o pensamento e a ação. Os profissionais podem se valer de teorias exaustivas (com foco em modelos detalhados de atuação); utilizar princípios teóricos para instrumentalizar intervenções com grande componente de improvisação e espontaneidade, ou ainda elaborar uma prática com bases predominantemente informais. Ampliar a formalização do trabalho - reduzindo seus elementos espontâneos e erráticos - seria fundamental, mas é uma questão complexa, que precisa ser abordada sem engessamento ou superficialidade.

A saída encontrada pelo autor é a defesa de um ecletismo teórico-prático. Conhecendo os limites e as possibilidades dos enfoques que pretende utilizar, os profissionais poderiam compatibilizá-los em benefício dos usuários, que seriam favorecidos por abordagens mais capazes de lidar com a complexidade de seus problemas e requisições.

Dessa forma, em Payne (2002, p. 85), o ecletismo se apresenta como

um ato cuidadoso e planeado, mais do que uma presunção de que "qualquer coisa serve". Uma abordagem sobre esta construção social sugere que uma construção partilhada teria frequentemente lugar em grupos profissionais que, respondendo às necessidades específicas de clientes servidos, os envolvem no seu desenvolvimento. Ao fazer isso, é, a meu ver, crucial compreender e considerar as ligações, oposições e consistências entre teorias, usando uma abordagem crítica [...].

Mesmo que tais palavras se dirijam sobretudo a possibilidades de combinação de abordagens voltadas ao trabalho direto com usuários (teorias sobre grupos, estigma, comportamento, trabalho com comunidades, escuta 
individual etc.), há que se notar que Payne (2002 e 2007) eleva a corolário de intervenção o amálgama teórico, já tão exposto à crítica por José Paulo Netto (2007). ${ }^{9}$

De fato, apesar dos alertas para o risco do ecletismo, as elaborações de Payne (2002) não são suficientes para pacificar o problema. O que ele apresenta não é a possibilidade de uso de diferentes técnicas (que em sua natureza instrumental poderiam ser adaptadas a diferentes princípios teóricos), mas a utilização justaposta ou interligada de variados conjuntos teórico-práticos, a partir de critérios e princípios de seleção pouco claros e sólidos.

A preocupação com as questões de coerência no método (atinentes aos padrões lógicos que subscrevem o pensamento que coordena a prática) sequer são notadas, o que abre caminho para compatibilização de correntes antagônicas ou para abordagens que reduziam as "teorias" a um conjunto de diretrizes de ação manualizadas, voltadas ao controle social dos usuários.

O que impede que Payne (2002) sucumba (cabalmente) diante de tais problemas é a visão de que a "teoria sobre a prática" consiste numa sistematização de saberes que orientam objetivamente a intervenção, a partir de fundamentos extraídos das ciências sociais, não sendo, portanto, uma cartilha definitiva e reducionista acerca do "como fazer" em cada situação de trabalho.

\section{Faleiros e o paradigma da correlação de forças}

O pensamento de Faleiros (2007 e 2013), um dos nomes mais decisivos da categoria no país e na América Latina, é de amplo conhecimento no debate brasileiro, já tendo sido alvo de análises e polêmicas variadas (Martins, 2014; Iamamoto, 2008). Exatamente por isso não cabe neste espaço realizar uma longa explanação, mas apenas recuperar os traços essenciais de suas ideias, de maneira a satisfazer os objetivos do texto presente.

9 Conforme Netto (2007), o ecletismo teórico é uma das características basilares do tradicionalismo profissional e diz respeito ao amálgama tanto das tradições do Serviço Social europeu e norte-americano, quanto das teorias e matrizes de pensamento que lhes davam suporte. 
De acordo com Faleiros (2009), o Serviço Social surge a partir das dinâmicas e contradições do capitalismo moderno, sobretudo quando estas provocam lutas políticas, protagonizadas por trabalhadores e movimentos sociais. A difusão e a consolidação da profissão nesse contexto se dá em um cenário específico: o do Estado keynesiano, com suas iniciativas de regulação do mercado e intervenção sistemática na vida social, por meio das políticas públicas sociais.

Segundo o autor, as políticas sociais, meios de regulação e reprodução social, deram origem a estruturas especializadas no desempenho de suas atividades: as instituições sociais, organizações que lidam com a administração dos conflitos distributivos, ocupando-se das várias políticas setoriais (criança e adolescente, habitação, saúde, educação e outras), por meio do provimento de atenção a três tipos de públicos: os trabalhadores, os inaptos para o trabalho e os "inaptos sociais" (doentes mentais, deficientes etc.).

As instituições sociais seriam lugares privilegiados para a atuação de diversos profissionais, dada sua demanda por prestadores de serviços com habilitação técnica. Nelas, segundo Faleiros (2009), os vários tipos ocupacionais estariam em constante competição por recursos, poder e visibilidade (isto é, por uma reserva de mercado que garanta seu espaço institucional), o que reforça comportamentos baseados na rotina e no segredo.

Assim, para Faleiros (2007), as instituições sociais passariam de mecanismos para o alcance de objetivos públicos a fins em si mesmas, transformando seus usuários em meios para a realização das metas institucionais e profissionais. De acordo com ele, é nesse contexto que a profissionalidade do assistente social é construída, demarcando tal agente como um operador de políticas sociais, um profissional de linha, e não de staff.

Em grande medida, a legitimidade do assistente social residiria na manipulação pequenos recursos junto às pessoas atendidas, estabelecendo com estas contatos próximos do nível pessoal. "Apesar disso, o profissional seria uma espécie de 'intelectual orgânico' com potencial para intervir nas disputas institucionais, favorecendo mais as classes dominantes ou as dominadas, dentro dos limites postos pelo real" (Martins, 2014, p. 69).

É importante ter em mente que as formulações de Faleiros (2007) apresentam grande influência do pensamento gramsciano (o próprio autor 
é pioneiro no estudo da obra de Gramsci no Serviço Social). Como bem nota Iamamoto (2008), a assimilação de tal debate por ele, no entanto, é incompleta, sem a remissão sistemática aos estudos gramscianos, com sua referência à cultura, às relações pedagógicas, ao trabalhador fordiano, à coerção e ao consenso na análise das temáticas da hegemonia e do Estado.

Em vez de tal aprofundamento, Faleiros (2009) se concentra na articulação das ideias gramscianas com as concepções mais avançadas das ciências sociais, sobretudo ao debate foucaultiano sobre o poder e a teoria dos capitais de Bourdieu. Aliás, é importante notar como tais influências se aprofundam ao longo do tempo, ganhando protagonismo, principalmente a partir de Saber profissional e poder institucional.

Com tais bases, o autor define o objeto profissional como as correlações de força e hegemonia que estruturam a prática dos assistentes sociais nos seus diferentes momentos, conjunturas e espaços sócio-ocupacionais. ${ }^{10}$

Dessa maneira, em Faleiros (2007 e 2011), o objeto de intervenção dos assistentes sociais seria uma relação de poder, que institui uma área no espaço social, que articularia instituições, profissionais e usuários. Tal campo apresentaria traços específicos, os quais tornariam possível um saber singular, que informaria uma disciplina com cientificidade própria.

Faleiros (2011), assim, apresenta a ideia de que o objeto do Serviço Social é histórico e fluido. A partir do caso brasileiro, nos anos 1930, ele pontua a articulação de um paradigma profissional conservador, que demarcava o objeto profissional na esfera da moral, da ordem e da higiene. Na ótica tradicional, a atuação do Serviço Social consistia em atividades de apoio psicoemocional e financeiro, de modo que o público usuário alcançasse "pequenos avanços" num cenário tido como deficiente (Faleiros, 2007).

Com o passar do tempo, mais especificamente no pós-guerra (período marcado pela consolidação do capitalismo monopolista, pelo autoritarismo

10 Nesse sentido, ele se distancia daqueles veem na questão social o objeto da profissão. Diz Faleiros (2011, p. 40) que o termo "questão social possui vários significados, e não pode ser tomado, sem uma definição rigorosa como objeto profissional [...]. Na atual conjuntura, os enfrentamentos de interesses, grupos, projetos, estão sendo vistos num processo complexo de relações de classe gênero, geração, raça, etnia, culturas, regiões, parentescos, trazendo à discussão as mediações da subjetividade e que não se resumem tout court na noção de questão social". 
político e pelo processo de industrialização no país), o autor identifica a ocorrência de um processo de desconstrução e reconstrução do objeto profissional, deslocado agora para a promoção tecnicista da harmonia social na relação Estado/sociedade - momento em que os assistentes sociais incorporaram a influência do ideário desenvolvimentista (principalmente por meio da difusão do chamado Serviço Social de comunidade).

Em outro estágio mais recente (que se estende do final dos anos 1970 até hoje), Faleiros (2011) relata um novo processo de mudança no objeto do Serviço Social, partir das transformações culturais dos anos 1960, do legado do Movimento de Reconceituação, da liberalização política do país e das alterações na sua estrutura econômica, com a marcante ascensão do neoliberalismo.

Nele, o objeto profissional flutuaria a partir de duas tendências divergentes: a burocratização de serviços sociais mercantilizados e minimalistas, por um lado, e dinâmicas de reprocessamento da cidadania, baseadas nos enfrentamentos de grupos de trabalhadoras e movimentos sociais, por outro.

Nesse sentido é possível discutir alguns cenários, levando em conta a perspectiva histórica até agora considerada. $O$ cenário burocrático-administrativo poderá ser reforçado pelo processo de privatização e terceirização, de redução do Estado, redução de pessoal, de corte nas políticas sociais, mas o processo de desinstitucionalização poderá abrir perspectivas novas de articulação da inserção social dos excluídos, de trabalho com as vítimas, de defesa dos direitos sociais. (Faleiros, 2011, p. 21)

Em tal contexto, os usuários dos serviços sociais (pobres, mulheres, idosos, crianças e adolescentes) se apresentam como crescentes demandatários das ações públicas e, ao mesmo tempo, consumidores atomizados e alienados de bens e serviços. Essa dualidade contemporânea pressiona a profissão, de forma que

a defesa de direitos, como pilar central e o eixo da atuação do Serviço Social, está sendo questionada pela valorização da focalização do trabalho social no indivíduo, e não mais no direito. Esta é a mudança que está se operando 
na prática profissional, não em função da adaptação do indivíduo à norma, e nem para garantia de direitos, mas para que tenha algumas condições, e mais que nunca, motivação para competir, por si mesmo, no mercado e gerar seus meios de vida. (Faleiros, 2013, p. 51)

Essas questões levam o autor a propor um novo paradigma profissional — o da correlação de forças - tido ao mesmo tempo como uma forma de análise da profissão e uma estratégia de intervenção. Nessa perspectiva, o trabalho profissional é visto como

confrontação de interesses, recursos, energias, conhecimentos, inscrita nos processos de hegemonia/contra-hegemonia, de dominação/resistência e conflito/consenso que os grupos sociais desenvolvem a partir de seus projetos societários básicos, fundados nas relações de exploração e de poder. Nesse sentido, os efeitos da prática profissional enquanto "suprir carências", "controlar perturbações" ou "legitimar o poder" implicam correlações de forças (mediações econômicas, políticas e ideológicas) [...]. Na particularidade do Serviço Social, é fundamental destacar a intervenção nas condições de vida e de trabalho (re-produzir-se) articuladas à formação da identidade individual e coletiva (re-presentar-se) na vinculação sujeito/estrutura [...]. O objeto do Serviço Social, como vimos, se constrói na relação sujeito/estrutura e na relação usuário/instituição em que emerge o processo de fortalecimento do usuário diante da fragilização de seus vínculos, capitais ou patrimônios individuais e coletivos. (Faleiros, 1999, p. 44).

O paradigma da correlação de forças se materializaria a partir da noção de empowerment (com base na ideia de capital social discutida por Bourdieu). O intuito seria mobilizar os patrimônios (ou capitais) dos usuários em termos de relações afetivas, redes de autoajuda e parentesco; os seus acessos a renda, bens e serviços públicos, de forma a enfrentar situações de fragilização e vulnerabilização social, ampliando o seu acesso a conhecimento, poder e recursos.

Em síntese, para Faleiros (2011 e 2013), o Serviço Social é uma profissão constituída por meio de uma relação de poder posta, sobretudo, dentro das políticas públicas, com suas instituições sociais. Isto é, "O Serviço Social se 
'fundamenta' na negação dos antagonismos do modo de produção capitalista. Ele atua, na prática, na camuflagem ou diminuição desses antagonismos" (Faleiros, 2009, p. 14).

Posto o caráter contraditório e mutável das relações sociais e, neste sentido, da própria categoria, aparece como factível a construção de uma atuação voltada para os interesses dos grupos populares e movimentos sociais.

\section{À guisa de conclusão}

O contraste entre o pensamento de Faleiros (2009 e 2013) e Payne (2002 e 2007) expõe as divergências consideráveis que existem entre os dois estudiosos, que encaminham suas assertivas sobre os fundamentos do Serviço Social, a partir de diferentes bases lógicas, distintas fontes teóricas e contextos sócio-ocupacionais (marxismo/teorias pós-modernas; Serviço Social brasileiro/Serviço Social europeu).

Temos em relação a Payne (2002 e 2007) uma análise focada diretamente na atuação profissional, isto é, na sistematização de diferentes perspectivas de instrumentalização do trabalho dos assistentes sociais, tentando conciliar objetivos profissionais, em boa medida, antitéticos e paradoxais.

Daí que Payne (2007) considere que a profissão seja uma instituição de trabalho, embasada por saberes, discursos e práticas estruturadas e academicamente legitimadas (as chamadas realidades imaginadas), voltada ao apoio a sujeitos e grupos com demandas públicas de reprodução social, e que encaminha suas ações a partir de enfoques de mudança social, ajustamento ou auxílio terapêutico.

Seu problema está, de fato, num formalismo que tenta amalgamar as visões mais díspares, a partir da frágil justificativa de que utilização de diferentes paradigmas e teorias sobre a prática tende a produzir respostas adequadas à complexidade dos problemas sociais dos usuários.

Falta ao autor, além disso, uma visão efetivamente capaz de elucidar as determinantes culturais, econômicas e políticas que impactam a profissão, possibilitando sua existência e desenvolvimento. Não aparecem com a 
importância que possuem pontos como o enfrentamento entre as classes sociais, os problemas postos pelo processo de urbanização/industrialização (que assentou a emergência da questão social), as pressões nos diversos contextos institucionais da profissão, fato que limita o alcance e a efetividade da análise empreendida.

Contudo, isto não significa a possibilidade de simplesmente descartar as concepções de Payne (2002). Suas contribuições ao debate profissional são reais. É notável o esforço de revisão da literatura profissional, que permite conhecer as mais diferentes perspectivas, principalmente no que toca às questões de intervenção.

Para além disso, a obra do autor se destaca pelas considerações práticas, com exemplos de atuação junto a famílias, idosos, deficientes, crianças e adolescentes, trabalho com doentes terminais, situações de crise etc. Cabe mencionar também a existência de problematizações ricas e úteis sobre o papel dos usuários na construção do corpus da categoria (explicitando que as expectativas e reações do público moldam as instituições empregadoras e contribuem para conformar a imagem e a autoimagem profissional); ou ainda a crítica ao Serviço Social ocidental, expondo os limites das suas contribuições para as sociedades com predominância rural.

Já Faleiros (2007, 2009 e 2013) observa o Serviço Social sob outro prisma, avaliando a profissão como uma relação particular de poder constituída no campo da reprodução e da regulação social no capitalismo moderno.

Os assistentes sociais, segundo ele, são profissionais de linha, que atuam diretamente com o público usuário, articulando os recursos das políticas públicas para atender a demandas originárias das desigualdades sociais, numa ordem burocrática institucional diretamente ligada ao conflito de classes.

O objeto profissional é visto como uma elaboração, um constructo histórico e mutável, determinado pela ordem social e pelas respostas profissionais dirigidas às requisições objetivas e subjetivas dos sujeitos atendidos. De acordo com Faleiros (2013), na cena contemporânea um perfil profissional competente é aquele capaz de superar o tradicionalismo que tanto marcou o Serviço Social, a partir de estratégias de trabalho efetivas, suficientes para 
deslocar o sentido da intervenção profissional, de uma ação predominantemente voltada para o ajustamento do sujeito, para uma prática afiançadora de direitos, promotora do fortalecimento individual e coletivo dos usuários.

Mesmo com problemas vinculados à incorporação seletiva de diversas teorias oriundas do pensamento social contemporâneo, ou questões envolvendo a precisão e a sistematicidade de sua escrita - como assevera Iamamoto (2008) —, o que temos em Faleiros (2009 e 2011) é uma visão crítica voltada para a totalidade social e que exprime a maturidade do Serviço Social brasileiro, bem como sua ruptura com o conservadorismo.

\section{Referências}

BERGER, P.; LUCKMANN, T. A construção social da realidade: tratado sobre a sociologia do conhecimento. 29. ed. Petrópolis: Vozes, 2008.

FALEIROS, V. de P. Estratégias em Serviço Social. 10. ed. São Paulo: Cortez, 2011. . Estratégias em serviço social. 2. ed. São Paulo: Cortez, 1999. Saber profissional e poder institucional. 7. ed. São Paulo: Cortez, 2007. . Metodologia e ideologia do trabalho social. 11. ed. São Paulo: Cortez, 2009. . Globalização, correlação de forças e Serviço Social. São Paulo: Cortez, 2013.

FERGUSON, I. Um outro Serviço Social é possível! Reivindicando a tradição radical. Em Pauta, Rio de Janeiro, v. 9, n. 27, jul. 2011.

IAMAMOTO, M. V. O Serviço Social em tempo de capital fetiche: capital financeiro, trabalho e questão social. 3. ed. São Paulo: Cortez, 2008.

MARTINS, L. R. Teoria das profissões e a análise dos fundamentos do Serviço Social. Verinotio, revista on-line de Filosofia e Ciências Humanas, n. 20, p. 64-81, out. 2014. Disponível em: <http://www.verinotio.org/conteudo/0.46616944434696.pdf>. Acesso em: 10 fev. 2018.

O pensamento de Jeannine Verdès-Leroux e o Serviço Social: um resgate crítico. Serviço Social \& Sociedade, São Paulo, n. 127, p. 514-532, dez. 2016.

A questão dos documentos profissionais no Serviço Social. Temporalis, Vitória, v. 33, n. 1, p. 75-102, jan./jun. 2017.

NETTO, J. P. Capitalismo monopolista e Serviço Social. 6. ed. São Paulo: Cortez, 2007.

PAYNE, M. Teoria do trabalho social moderno. 2. ed. Coimbra: Quarteto, 2002. 
PAYNE, M. Social Work and community care. Londres: Macmillan International Higher Education, 1995. What is professional Social Work? Chicago: Lyceum Books, 2007. . Humanistic Social Work: core principles in practice. Chicago: Lyceum Books, 2011.

TEIXEIRA, J. B. O projeto ético-político e às relações internacionais. Revista Inscrita, Brasília, n. 10, p. 47-54, 2007.

\section{Sobre o autor}

Ludson Rocha Martins - Mestre em Serviço Social pela Universidade Federal de Juiz de Fora (UFJF).

E-mail: ludsonrocha@gmail.com 